\title{
Influence of lifestyle on oral health behavior among rural residents of Udaipur district, India
}

\author{
Santhosh Kumar ${ }^{1}$, Anshika Nigam ${ }^{2}$, Alka Choudhary ${ }^{2}$, Jyothi Tadakamadla ${ }^{3}$, Harish Tibdewal ${ }^{4}$, Prabu \\ Duraiswamy $^{5}$, Suhas Kulkarni ${ }^{6}$
}

\footnotetext{
${ }^{1}$ Senior lecturer, Department of preventive and community dentistry

${ }^{2}$ Under graduate student, Department of preventive and community dentistry

${ }^{3}$ Jyothi Tadakamadla, Senior lecturer, Department of oral medicine \& Radiology

${ }^{4}$ Post graduate student, Department of preventive and community dentistry

${ }^{5}$ Associate Professor, Department of preventive and community dentistry

${ }^{6}$ Professor, Department of preventive and community dentistry
}

Correspondence:

Department of preventive and community dentistry

Vishnu Dental College

Bhimavaram. India. 534202

santosh_dentist@yahoo.com

Received: 18/04/2010

Accepted: 27/06/2010

Kumar S, Nigam A, Choudhary A, Tadakamadla J, Tibdewal H, Duraiswamy $\mathrm{P}$, Kulkarni S. Influence of lifestyle on oral health behavior among rural residents of Udaipur district, India. Med Oral Patol Oral Cir Bucal. 2011 Sep 1;16 (6):e828-33.

http://www.medicinaoral.com/medoralfree 01/v16i6/medoralv16i6p828.pdf

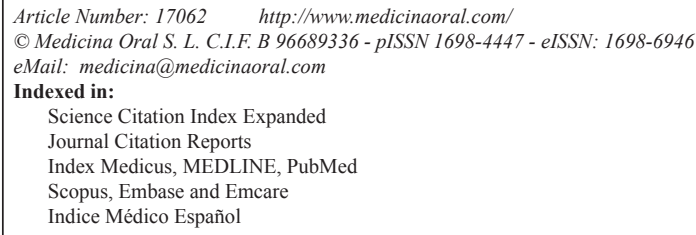

\begin{abstract}
Objectives: To determine the relation of life style with dental health behavior such as tooth brushing frequency, use of extra cleansing devices and regular visits to dentist among rural residents of Udaipur district, India.

Study design: The study population comprised of 1001 rural population between the ages 18 to 69 years selected by multi stage stratified cluster sampling procedure. Personal interviews were conducted by three trained interviewers who collected information on socio-demographic and lifestyle factors in addition to some aspects of dental health behavior including tooth brushing frequency, use of extra cleaning devices like dental floss and regular visits to dentist.

Results: Majority of the population (63.3\%) brushed their teeth once a day and only a few subjects (19.8\%) brushed twice a day whereas $8.6 \%$ never brushed their teeth. Logistic regression analysis revealed that females were more apt in every aspect of dental health behavior. House wives were more regular in brushing their teeth $(\mathrm{OR}=1.51)$ and using extra cleansing devices as compared to other occupation groups. Subjects who suffered from systemic disease showed negative association with use of extra cleansing devices but showed positive association with regular visits to dentist.

Conclusions: The results indicate that dental health behavior is related with life style factors as well as sociodemographic variables.
\end{abstract}

Key words: Tooth brushing, extra cleansing devices, regular visits to dentist, lifestyle, rural population. 


\section{Introduction}

The concept of lifestyle makes it possible to study behavior in wider sense and it sheds more light on the personal characteristics of individual than earlier investigations which include only dental health habits or smoking habits (1).

Health care behavior such as regular physical activity, balanced diet and use of seatbelts have also been found to be associated with each other, these observed interrelationship have not always been found consistently and may vary over time (2).

Dental health behavior has been associated with general health behavior, gender, education, income, smoking, alcohol consumption or dietary habits, behavior of parents, physical and social activity (3-6).

Prochaska stated that health related behavior change would reduce the unhealthy behavior such as sugar in diet and smoking as well increase health behavior such as flossing and dental attendance (7).

In US adult population, daily brushing has been shown to be significantly related to education and income while family characteristics and dental health behavior of parents was related to the regular dental visits by the adolescents (8).

In addition it was observed self efficacy in dental care to be associated with cognitive, experiential, supportive and emotional dimensions, and beliefs and values learned in the family and at school (9).

To help adults maintain sound teeth the ADA recommends that an individual should brush twice and floss once a day and have regular prophylactic dental visits. Oral health behavior data are needed for planning and evaluation of health promotion programs and systemic analysis of oral health behavior may help the specification of oral health messages as well as development of behavior modifications strategies.

Socio epidemiological data on oral health behavior are scarce and in particular systemic data on oral health behavior of rural population are not available at national level.

Thus, the present study aimed to determine various life style factors that affect dental health behavior such as tooth brushing frequency, use of extra cleansing devices and regular visits to dentist among rural residents of Udaipur district, India.

\section{Materials and Methods}

The study population comprised of 1001 rural population of Udaipur district, Rajasthan between the ages 18 to 69 years. Stratified random sampling procedure was executed to collect the representative sample. Udaipur district is divided geographically into 7 sub divisions and has 2393 inhabited villages.

The seven subdivisions of the district constituted the strata and one village was randomly selected from each subdivision. From each of the selected village, all the households were covered, starting from northeast corner of the village. Informed consent was obtained from the village leaders and heads of the concerned households, before carrying out the survey.

Survey was conducted during holidays and in the evenings, individuals present at home on the days of the survey between the ages of 18 to 69 years were included in the study and exclusion criterion comprised the subjects unwilling to participate.

Personal interviews were conducted by three trained interviewers who collected information on socio-demographic factors (age, sex and occupation) and lifestyle factors in addition to dental health behavior including tooth brushing frequency, use of extra cleaning devices and regular visits to dentist. Questions for the assessment of lifestyle included number of family members, alcohol consumption, smoking, dietary habits and presence of systemic disease in accordance to a previous survey (6).

Questionnaire also included mental health assessment like duration of sleep, consumption of alcohol or medicine for the purpose of falling asleep, effectiveness of sleep for over coming fatigue and mental stress. Physical and social activities were assessed by frequency of active movement, extra physical exercise, social volunteer work and number of intimate friends and relatives. Ethical approval was availed from the Ethical Committee for Research of Darshan Dental College and Hospital.

Data collected was entered into the spread sheets and SPSS (Statistical Package for Social Sciences) version 11.0 was used for statistical analysis.

Multiple logistic regression analyses (all variables entered) was executed to determine the association between various dependent and independent variables. Dependent variables comprised of tooth brushing frequency ( $1=$ twice a day, $0=\leq$ once in a day), use of extracleansing devices ( $1=$ regularly, $0=$ never/sometimes/ often) and regular visits to dentists $(1=$ yes, $0=$ no) which were dichotomized.

Independent variables comprised of age, gender, occupation, number of family members, current mental health status, duration of sleep, taking alcohol or medicine for falling sleep, effectiveness of sleep for overcoming fatigue, feeling stress, alcohol consumption, smoking, physical activities, social volunteer work, worthy life, number of intimate friends, eating breakfast, degree of likes and dislikes of food, attention to dietary combination, attention to sugar intake, attention to salt intake and systemic disease.

\section{Results}

A total of 1200 residents were selected for inclusion into the study, of which 1001 subjects responded (response 
rate $=84.4 \%$ ). Table 1 shows the percentage distribution of respondents by age, gender and oral health behavior. More than half $(66.8 \%)$ the population belonged to middle age group (30-49) and there were few participants from the oldest (2.5\%) age group.

Majority of the population (63.3\%) brushed their teeth once a day and only a few subjects $(19.8 \%)$ brushed twice a day whereas $8.6 \%$ never brushed their teeth. Moreover, $19.5 \%$ of the study population used extra cleansing devices regularly and nearly half the population $(49 \%)$ never used them.

Approximately three quarters of the population had never visited the dentist regularly.

Table 2 shows the relationship between the dental health behaviors and all the independent variables analyzed using bivariate logistic regression analysis. Only those variables which showed significant relationship are presented in the table.

Females were more apt in every aspect of dental health behavior. Occupation showed relation with brushing frequency, regular dentist visits and use of extra cleansing devices; housewives were more regular in brushing their teeth $(\mathrm{OR}=1.51)$ and using extra cleansing devices as compared to other occupation groups. As the number of family members increased regular visits to dentist increased as in case of 6- 10 family members $(\mathrm{OR}=1.20)$, but usage of extra cleansing device in this group was minimum $(\mathrm{OR}=0.02)$.

Subjects who consumed alcohol or medicine for falling sleep occasionally or every day were less habitual for regular visits to dentist, while the residents who experienced stress sometimes, often or always were less used to all the oral hygiene habits. The residents who were never involved or sometimes involved in physical activities showed strong negative relation with all the dental hygiene habits.

Furthermore, the population who were never or sometimes involved in social activities showed strong negative association with tooth brushing frequency and extra cleansing device but were more regular in dental visits. Participants who felt their life not worthy were not interested in regular dental check up but those who were having less than 3 intimate friends were regular for dental visits. Tooth brushing frequency was not associated with consideration to dislikes and likes of food and dietary combination whereas the usage of extra cleansing devices was not associated with consideration to salt and sugar intake.

The study subjects who suffered from systemic disease showed negative association with use of extra cleansing devices but showed positive association with regular visits to dentist.

The subjects with good current mental health status were associated with increase in tooth brushing frequency $(\mathrm{OR}=1.82)$ and the subjects who slept for 7-9
Table 1. Distribution of subjects according to age, gender, tooth brushing frequency, use of extra cleansing devices and regular visits to dentist.

\begin{tabular}{|c|c|c|}
\hline & Number & Percentage \\
\hline \multicolumn{3}{|l|}{ Age } \\
\hline $18-29$ & 129 & 12.9 \\
\hline $30-39$ & 324 & 32.4 \\
\hline $40-49$ & 345 & 34.4 \\
\hline $50-59$ & 178 & 17.8 \\
\hline $60-69$ & 25 & 2.5 \\
\hline \multicolumn{3}{|l|}{ Gender } \\
\hline Male & 486 & 48.6 \\
\hline Female & 514 & 51.4 \\
\hline \multicolumn{3}{|c|}{ Tooth brushing frequency } \\
\hline Once a day & 634 & 63.3 \\
\hline Twice a day & 198 & 19.8 \\
\hline Once a week & 83 & 8.3 \\
\hline Never & 86 & 8.6 \\
\hline \multicolumn{3}{|c|}{ Extra cleansing devices } \\
\hline Never & 490 & 49.0 \\
\hline Sometimes & 302 & 30.2 \\
\hline Regularly & 195 & 19.5 \\
\hline Often & 14 & 1.4 \\
\hline \multicolumn{3}{|c|}{ Regular visits to dentist } \\
\hline Yes & 248 & 24.8 \\
\hline No & 752 & 75.2 \\
\hline
\end{tabular}

hours showed more interest in use of extra cleansing devices $(\mathrm{OR}=1.16)$. Smokers used extra cleansing devices less frequently $(\mathrm{OR}=0.77)$ and alcohol consumers were irregular in dental visits $(\mathrm{OR}=0.72)$.

\section{Discussion}

In Udaipur district, socio-epidemiological data on oral health behavior are scarce and only one local oral health report is available on rural adults. Many past studies suggest that lifestyle factors significantly influence the oral health behaviors of the population which in turn determine the oral health status. Hence the present study 
Table 2. Relationship between lifestyle and dental health behavior.

\begin{tabular}{|c|c|c|c|}
\hline & $\begin{array}{l}\text { Tooth brushing frequency } \\
\text { (twice per day or more) }\end{array}$ & $\begin{array}{l}\text { Use of extra cleaning devices } \\
\text { (several times or more) }\end{array}$ & Regular visits to dentist (yes) \\
\hline \multicolumn{4}{|l|}{ Gender } \\
\hline Male & $0.59(0.35-0.81)^{* *}$ & $0.83(0.33-2.09)$ & $0.66(0.32-0.92)^{*}$ \\
\hline \multicolumn{4}{|l|}{ Occupation } \\
\hline $\begin{array}{l}\text { House wife } \\
\text { Farmer }\end{array}$ & $\begin{array}{l}1.51(0.81-2.78) \\
0.94(0.50-1.75)\end{array}$ & $\begin{array}{c}4.24(1.27-14.15)^{* *} \\
0.89(0.56-.98)\end{array}$ & $\begin{array}{c}0.87(0.35-2.18) \\
0.42(0.19-0.93)^{*}\end{array}$ \\
\hline \multicolumn{4}{|l|}{ No. of family members } \\
\hline $\begin{array}{l}6-10 \\
<5\end{array}$ & $\begin{array}{l}0.10(0.05-0.21)^{* * *} \\
1.19(1.09-1.68)^{* * *}\end{array}$ & $\begin{array}{l}0.02(0.006-1.07) \\
0.04(0.001-1.93)\end{array}$ & $\begin{array}{l}1.20(0.49-2.91) \\
0.76(0.32-1.82)\end{array}$ \\
\hline \multicolumn{4}{|c|}{ Current mental health status } \\
\hline Good & $1.82(0.50-2.35)$ & $1.25(1.14-2.91)^{* *}$ & $0.39(0.19-0.77)^{* *}$ \\
\hline \multicolumn{4}{|l|}{ Duration of sleep } \\
\hline $7-8 \mathrm{hrs}$ & $1.54(1.36-1.82)^{* *}$ & $1.16(0.55-2.43)$ & $0.11(0.006-0.21)^{* * *}$ \\
\hline \multicolumn{4}{|c|}{ Taking alcohol/medicine for falling sleep } \\
\hline Occasionally/everyday & $0.84(0.53-1.32)$ & $0.61(0.30-1.24)$ & $0.59(0.20-0.85)^{* *}$ \\
\hline \multicolumn{4}{|l|}{ Feeling stress } \\
\hline Sometimes/ often/ always & $0.12(0.007-0.21)^{* * *}$ & $0.031(0.014-0.069)^{* * *}$ & $0.59(0.28-0.94)^{* * *}$ \\
\hline \multicolumn{4}{|l|}{ Alcohol consumption } \\
\hline Sometimes/ often/always & $0.78(0.23-0.80)^{*}$ & $0.83(0.37-0.90)^{* * *}$ & $0.72(0.40-1.29)$ \\
\hline \multicolumn{4}{|l|}{ Smoking } \\
\hline Sometimes/ often/always & $0.38(0.22-0.64)^{* * * *}$ & $0.77(0.36-1.61)$ & $0.55(0.33-0.81)^{* *}$ \\
\hline \multicolumn{4}{|l|}{ Physical activity } \\
\hline Never/sometimes & $0.06(0.03-0.09)^{* * * *}$ & $0.09(0.038-0.09)^{* * *}$ & $0.98(0.52-0.99)^{* *}$ \\
\hline \multicolumn{4}{|l|}{ Social volunteer work } \\
\hline Never/ sometimes & $0.39(0.21-0.73)^{* *}$ & $0.10(0.02-0.26)^{* * *}$ & $2.32(1.16-4.64)^{* *}$ \\
\hline \multicolumn{4}{|l|}{ Worthy life } \\
\hline No & $0.85(0.65-1.70)$ & $0.72(0.46-1.25)$ & $0.58(0.13-0.89)^{* * *}$ \\
\hline \multicolumn{4}{|l|}{ No. of intimate friends } \\
\hline$<3$ & $0.37(0.60-1.31)$ & $0.73(0.38-1.40)$ & $2.23(1.34-3.71)^{* *}$ \\
\hline \multicolumn{4}{|l|}{ Eating breakfast } \\
\hline Sometimes & $0.65(0.41-1.62)$ & $0.67(0.15-0.87)^{* * *}$ & $2.18(1.43-3.18)^{* * *}$ \\
\hline \multicolumn{4}{|c|}{ Degree of likes \& dislikes of food } \\
\hline Slight/none & $0.45(0.27-0.74)^{* * *}$ & $0.58(0.27-1.25)$ & $0.81(0.46-1.45)$ \\
\hline \multicolumn{4}{|c|}{ Attention to dietary combination } \\
\hline Never & $0.69(0.15-0.83)^{* * *}$ & $0.74(0.54-1.91)$ & $0.35(0.14-1.66)$ \\
\hline \multicolumn{4}{|l|}{ Attention to sugar intake } \\
\hline Never & $1.60(0.96-2.65)$ & $0.28(0.12-0.62)^{* *}$ & $0.78(0.39-0.96)^{* * *}$ \\
\hline \multicolumn{4}{|l|}{ Attention to salt intake } \\
\hline Never & $0.64(0.40-1.03)$ & $0.45(0.27-0.85)^{* *}$ & $0.45(0.24-0.85)$ \\
\hline \multicolumn{4}{|l|}{ Systemic disease } \\
\hline Yes & $0.67(0.43-1.06)$ & $0.09(0.04-0.09)^{* * *}$ & $2.29(1.26-4.18)^{* *}$ \\
\hline
\end{tabular}

$* \mathrm{p}<0.05 \quad * * \mathrm{p}<0.01 \quad * * * \mathrm{p}<0.001$

Reference categories: Females, Other occupations, $>10$ family members, Poor mental status, 6 or $>9$ hrs sleep, not taking alcohol/medicine to sleep, sleep is effective in overcoming fatigue, never felt stress, never consumed alcohol, never smoked, perform physical activity often/regularly, indulge in social volunteer work often/always, feel life worthy, 3 or more friends, always have breakfast, much/moderate likes and dislikes of food, always/sometimes pay attention to dietary combination, always/sometimes pay attention to sugar intake, always/sometimes pay attention to salt intake, suffering from systemic disease. 
aimed to assess the lifestyle factors that influenced oral health behavior among rural residents of Udaipur district, India.

Stratified sampling procedure was executed to collect representative sample from the heterogeneous population of the district. Moreover, survey was conducted during holidays and in the evenings when most of the people stay at home.

According to the National oral health survey, the percentage of rural population who brush their teeth twice a day or more was 7\% nationally and 5.7\% in Udaipur district among 35-44 year old individuals in contrast to $19.8 \%$ in the present study population.

The difference in the levels of tooth brushing behavior observed in the present study from the past survey might be due to the difference in the methodological aspects. In the past survey of the district, 15 villages were selected randomly without conducting any stratification thus the sample of the past survey may not be representative of the district.

Females were more apt than were males in brushing their tooth frequently, using extra cleaning devices and regular dental visits which is supported by many past studies $(1,2,4,5,10-12)$.

The reason for more frequent tooth brushing by females has been reported to be esthetics and social norms $(1,13)$. Among 1001 rural residents of Udaipur district, 63.3\% brushed their teeth once in a day and only $19.5 \%$ used the extra cleansing devices, the present finding is more modest than that of a previous study from Burkina Faso, where it was observed that $57 \%$ of $35-44$ year old brushed their teeth on a daily basis (14).

It was observed that the subjects in manual occupations (farmers and laborers) exhibited poorer oral hygiene behavior than individuals in other occupations. Moreover, housewives were more regular in brushing their teeth and using extra cleansing devices compared to other occupation groups; this could be attributed to enough time available for housewives at home so they could spend more time for oral hygiene maintenance compared to other occupational groups.

Astrom and Rise (15) observed that significant relationship exists between health enhancing behavior and occupational status.

A previous study (16) among the medical students found mental stress to adversely affect oral health and oral health behavior. The present study supports this study and it also shows that the frequent feeling of stress and inadequate or excessive sleep are significantly related to poor oral hygiene habits.

The residents who were involved in physical activities and consumed breakfast less frequently showed strong negative relation with dental hygiene habits. Additionally, smokers and alcohol consumers reported poor oral hygiene behavior.
This is in agreement with a study among Japanese adult population which observed tooth brushing frequency to be significantly correlated with smoking, drinking, physical exercise and eating breakfast (3).

Subjects living with less than 5 family members were more pertinent in tooth brushing behavior than were the subjects living together with many family members, in coincidence with observations among Japanese rural population (6). A significant effect of the parental characteristics on regular visit to dentist has been reported (17) and studies among English (18) and Scottish school children (2) found that lifestyle influence the tooth brushing practice in adolescents.

The present study also showed relation of social activity (social volunteer work) with dental health behavior, the individuals who volunteer social work rarely were less likely to brush their teeth twice daily and use extra cleansing devices but were more likely to visit dentist. Socio cultural factors and material living conditions and participation in a social network were significantly associated with the use of oral health care services by adults (19).

In agreement with previous findings, $(3,20,21)$ the present study showed strong positive association between tooth brushing frequency and attention to sugar intake, indicating that habits related to dental health exist in the same direction.

Subjects with systemic diseases were less likely to brush their teeth and use extra cleansing devices but were more regular in visiting dentist in accordance to Harada et al. (6).

In conclusion, the results of the present study indicate that dental health behavior is associated with lifestyle factors as well as various socio-demographic variables like gender and occupation. Stress, physical activity and social volunteer work were significantly related to tooth brushing frequency, use of extra cleansing devices and dental visits. Family size, smoking, alcohol consumption and dietary attention markedly affected toothbrushing frequency too. All the significant lifestyle factors except family size, alcohol consumption and attention to dietary combination influenced dental visiting behavior.

Extra cleansing habits were more frequently practiced by housewives, non alcoholics, subjects with good mental status and systemic health, individuals paying dietary attention and those performing regular physical activities.

\section{References}

References with links to Crossref - DOI

1. Sakki TK, Knuuttila ML, Vimpari SS, Hartikainen MS. Association of lifestyle with periodontal health. Community Dent Oral Epidemiol. 1995;23:155-8.

2. Schou L, Currie C, McQueen D. Using a "lifestyle" perspective to understand toothbrushing behaviour in Scottish schoolchildren. Community Dent Oral Epidemiol. 1990;18:230-4. 
3. Tada A, Matsukubo T. Relationship between oral health behaviors and general health behaviors in a Japanese adult population. J Public Health Dent. 2003;63:250-4.

4. Rajala M, Honkala E, Rimpelä M, Lammi S. Toothbrushing in relation to other health habits in Finland. Community Dent Oral Epidemiol. 1980;8:391-5.

5. Lo EC, Lin HC, Wang ZJ, Wong MC, Schwarz E. Utilization of dental services in Southern China. J Dent Res. 2001;80:1471-4.

6. Harada S, Akhter R, Kurita K, Mori M, Hoshikoshi M, Tamashiro

$\mathrm{H}$, et al. Relationships between lifestyle and dental health behaviors in a rural population in Japan. Community Dent Oral Epidemiol. 2005;33:17-24.

7. Prochaska JO. Strong and weak principles for progressing from precontemplation to action on the basis of twelve problem behaviors. Health Psychol. 1994;13:47-51.

8. Payne BJ, Locker D. Relationship between dental and general health behaviors in a Canadian population. J Public Health Dent. 1996;56:198-204.

9. Syrjälä AM, Knuuttila ML, Syrjälä LK. Self-efficacy perceptions in oral health behavior. Acta Odontol Scand. 2001;59:1-6.

10. Payne BJ, Locker D. Oral self-care behaviours in older dentate adults. Community Dent Oral Epidemiol. 1992;20:376-80.

11. Sakki TK, Knuuttila ML, Anttila SS. Lifestyle, gender and occupational status as determinants of dental health behavior. J Clin Periodontol. 1998;25:566-70.

12. Källestål C, Dahlgren L, Stenlund H. Oral health behavior and self-esteem in Swedish adolescents over four years. J Adolesc Health. 2006;38:583-90.

13. Hodge HC, Holloway PJ, Bell CR. Factors associated with toothbrushing behaviour in adolescents. Br Dent J. 1982;152:49-51.

14. Varenne B, Petersen PE, Ouattara S. Oral health behaviour of children and adults in urban and rural areas of Burkina Faso, Africa. Int Dent J. 2006;56:61-70.

15. Astrøm AN, Rise J. Socio-economic differences in patterns of health and oral health behaviour in 25 year old Norwegians. Clin Oral Investig. 2001;5:122-8.

16. Deinzer R, Granrath N, Spahl M, Linz S, Waschul B, Herforth A. Stress, oral health behaviour and clinical outcome. Br J Health Psychol. 2005;10:269-83.

17. Scott G, Brodeur JM, Olivier M, Benigeri M. Parental factors associated with regular use of dental services by second-year secondary school students in Quebec. J Can Dent Assoc. 2002;68:604-8.

18. Macgregor ID, Balding JW. Toothbrushing and smoking behaviour in 14-year-old English schoolchildren. Community Dent Health. 1987;4:27-34.

19. Varenne B, Petersen PE, Fournet F, Msellati P, Gary J, Ouattara $\mathrm{S}$, et al. Illness-related behaviour and utilization of oral health services among adult city-dwellers in Burkina Faso: evidence from a household survey. BMC Health Serv Res. 2006;6:164.

20. Macgregor ID, Balding JW. Toothbrushing frequency in relation to family size and bedtimes in English schoolchildren. Community Dent Oral Epidemiol. 1987;15:181-3.

21. Kleemola-Kujala E, Räsänen L. Relationship of oral hygiene and sugar consumption to risk of caries in children. Community Dent Oral Epidemiol. 1982;10:224-33. 